\title{
Imaginaciones rurales argentinas: el campo como zona de cruce en expresiones artísticas contemporáneas
}

\author{
Argentinian Rural Imaginations: The Countryside as the \\ Crossroads of Contemporary Artistic Expressions \\ Imaginações rurais argentinas: o campo como zona de \\ cruzamento em expressões artísticas contemporâneas
}

\section{Lucía De Leone}

UNIVERSIDAD DE BUENOS AIRES/CONSEJO NACIONAL DE INVESTIGACIONES CIENTÍFICAS Y TÉCNICAS, ARGENTINA

Ha dictado cursos y seminarios sobre literatura argentina y latinoamericana

en Universidad Nacional de San Martín y en la Universidad

Nacional de Luján, y en 2015 en la Facultad de Filosofía y Letras de

la Universidad de Buenos Aires (UBA). Doctora en Letras (UBA) e investigadora del Consejo Nacional de Investigaciones Científicas

y Técnicas (Conicet). Es coeditora del libro Escrito en el viento.

Lecturas sobre Sara Gallardo (Buenos Aires: UBA, 2013), y preparó y prologó la edición de Almafuerte y El libro humilde y doliente de Salvadora Medina Onrubia (Buena Vista, 2014). Asimismo, hizo la selección, el estudio preliminar y las notas del libro Sara Gallardo. Macaneos. Las columnas de Confirmado (1967-1972) (Winograd, 2015). Ha publicado artículos en libros especializados y revistas académicas nacionales e internacionales. Se desempeña como secretaria de redacción de Mora, revista del Instituto Interdisciplinario de Estudios de Género. Correo electrónico: lmdeleone@gmail.com

Artículo de reflexión

Documento accesible en línea desde la siguiente dirección: http://revistas.javeriana.edu.co doi:10.11144/Javeriana.cl20-40.irac 


\section{Resumen}

En los últimos años se ha podido identificar en las artes argentinas un creciente interés por los motivos rurales, que coincide, en los planos político y económico, con un momento en que el campo se afirma como centro de atención, un agente de disputa entre sectores y materia productora de nuevos relatos, y en el plano cultural, con un conjunto de especulaciones teórico-críticas que se interrogan sobre el estado del arte del presente. En este artículo se indaga cómo la imaginación artística contemporánea (literatura, cine y teatro) procesa esta revisibilización del campo, que alcanza también otros formatos y productos mediáticos (un reality show), y cómo estas expresiones conviven muchas veces sin diálogo ni engarces, pero también sin conflicto.

Palabras clave: imaginaciones rurales; género; cultura argentina contemporánea

\section{Abstract}

During the last few years it became possible to identify in Argentinian arts a growing interest for rural motifs, coinciding with the political and economic areas, in a moment where the countryside solidifies as a focus of attention. It became the cause for arguments between sectors and material for new stories, and, in the cultural area, for a group of theoretical and critical speculations questioning the state of current art. This article delves into how the contemporary artistic imagination (literature, cinema, and theater) processes the resurgence of the countryside, reaching up to other different formats and media products (a reality show), and how these expressions most of the time coexist without dialogue or linkages, and yet, without conflict.

Keywords: rural imaginations; genre; contemporary Argentinian culture

\section{Resumo}

Nos últimos anos pode-se identificar nas artes argentinas crescente interesse por motivações rurais, que nos planos político e econômico coincide com um momento em que o campo é reafirmado como centro de atenção, agente de disputa entre setores e matéria produtora de novos relatos, e no plano cultural, com um conjunto de especulações teórico-críticas que se questionam sobre o estado da arte do presente. Neste artigo investiga-se como é que a imaginação artística contemporânea (literatura, cinema e teatro) processa tal revisibilização do campo, que mesmo atinge outros formatos e produtos mediáticos (um reality show), e como essas expressões convivem muitas vezes sem diálogo nem travação, contudo sem conflito.

Palavras-chave: imaginações rurais; género; cultura argentina contemporânea 


\section{Tres escenas literarias}

I. En 1968, en el contexto del llamado boom de la literatura hispanoamericana, la escritora argentina Sara Gallardo (1931-1988) publica con éxito Los galgos, los galgos, una novela cuyo título anuncia repeticiones, y que, deudora de la tradición de la novela de ambientación rural, retoma la parábola ciudad-campo-Parísciudad-campo, y el itinerario de aprendizajes truncos del joven heredero de la élite criolla.

Sin duda, la narrativa rural dejó de producirse hace mucho, y ya las de Ricardo Güiraldes fueron tardías novelas rurales. Tampoco las de Gallardo escaparon, injustamente, al relego en el cajón de lo epigonal, lo anacrónico, o al prejuicio de una lectura biograficista y de clase que se traduciría en una fórmula del tipo: la hija de patrones de estancia que escribe sobre el campo.

Si menciono aquí esta novela es porque hacia el final pareciera decretarse metaficcionalmente una suerte de agotamiento del ruralismo literario. En los últimos párrafos, el joven heredero, Julián, protagonista y narrador, llega desencantado de París, y de la ciudad se vuelve al campo. Baja del tren, camina, salta tranqueras, llega a su estancia, que está deteriorada. Justo entonces se abandona el yo autobiográfico que reguló la novela, y se da paso a una tercera persona extradiegética (acaso sea la de la misma autora) que enuncia el hartazgo, también la sospecha, ante la imagen del hombre a campo traviesa, y hasta prefigura su fin: "Un hombre a pie por la llanura tiene algo de escandaloso. Algo de paria, algo de asesino que huye, algo de ridículo, algo de despreciable, algo de sospechoso" (Gallardo 395). Para este hombre se baraja además una opción más: "caer muerto y ser comido por los caranchos" (395).

¿Qué será de Julián en ese retorno? ¿Se reinstalará en la estancia ahora estéril? ¿Se correrá de escenario? ¿Será un criminal, será carroña, un resto más? ¿Sobrevivirá a los caranchos? Esa historia que la novela no resuelve podría ser una de las tantas por revitalizar o rescribir de allí en adelante.

II. En un momento de su juventud, Elena Arteche, la protagonista de la novela El desperdicio (2007) de Matilde Sánchez (1958- ), planea irse de la casa de su infancia, ubicada en Pirovano, un pueblo del partido de Bolívar de la provincia de Buenos Aires, cuya riqueza se funda en las actividades rurales. El periplo de Elena es desde el pueblo bonaerense a la ciudad capital, que a fines de los años setenta "conservaba su aura de ciudad literaria" (29). Antes de convertirse en una destacada crítica literaria, Elena se impone la meta de evadirse de toda esa "destilería de bosta" (29), una expresión en la que bosta no solo funciona como sinécdoque de los desperdicios escatológicos del mundo ganadero, sino que también alude a lo que Elena denomina, en evidente paráfrasis de la célebre frase de Sarmiento de 
la "aristocracia con olor a bosta", "la clase bostera" (170). Pero, además de todo, esa expresión alude al intento por parte de Elena de evadir una tradición literaria: las novelas de ambientación rural. Irse implica no volver allí de ninguna manera, y seguir el camino contrario al de "la Gallardo", cuya salida de la estancia familiar constituye - según la protagonista de Sánchez- el punto de partida para dar una vuelta atrás: "irse para seguir escribiendo novelas rurales" (29).

Finalmente, Elena vuelve, enferma, a un campo desmantelado que poco tiene que ver con su pasado de prosperidad. Sin embargo, como señaló Sylvia Molloy, el regreso de Elena, antes que pensarse fácilmente como mero desperdicio de una intelectual-promesa a un campo también devastado, podría leerse -en el cruce género, intelecto, espacio nacional- como un nuevo acercamiento al problema del campo, como una revitalización del lugar conocido: ya sea en la trama y la "pedagogía salvaje" que practica en su vuelta el personaje femenino; en la novela sobre el campo que escribe la escritora en un contexto sociopolítico y económico peculiar (después de la crisis de 2001 pero previo al llamado problema del campo), o incluso en los modos selectivos en que se intercepta una tradición literaria fundacional y se abre una genealogía hacia adelante de nuevas narradoras que escriben el campo.

III. La breve novela El viento que arrasa (2012) dio en los últimos años a su autora, Selva Almada (1973- ), una gran visibilidad, evidenciada, por caso, en el éxito de ventas, reediciones, traducciones a otras lenguas, el entusiasmo de la crítica, pero también en la presencia de la escritora en rankings literarios, y festivales, eventos culturales y ferias del libro locales e internacionales. Sobre ella gravitan diversos juicios críticos; por ejemplo, el de Beatriz Sarlo, que apunta a la originalidad de su literatura no urbana, de provincia, y que revisita imaginarios rurales; también, el de Oliverio Coelho, que la emparenta con la Sara Gallardo cuentista, la de El país del humo (1977) - donde se revierten o inventan mitos, sueños, fábulas americanos y nacionales- por el hiperrealismo en que se resuelven algunas zonas fantasmagóricas de su novela, o el de Álvaro Fernández Bravo, que analiza en El viento que arrasa instancias narrativas de contaminación y convivencia cronológica: las heterocronías.

Almada ha venido situando sus ficciones en escenarios no metropolitanos, en lugares de transición: el afuera del pueblo, el pueblito de provincia donde se palpita el campo o, como en la celebrada novela, a la vera de una ruta inhóspita del norte del país. ${ }^{1}$ Para los personajes de El viento que arrasa, el campo es un espacio

1 En su producción el campo siempre aparece cerca y en la mira: como lugar familiar donde pasar las vacaciones, y reducto de impactantes leyendas en su autobiográfico Una chica de 
inmediato - está "a unos quinientos metros" (128) - y disponible para los que están atrapados en el taller mecánico (el gringo Brauer y su ahijado Tapioca) y para los que llegan ahí por casualidad (el reverendo Pearson y su hija Leni tras la avería del auto que detiene su marcha evangelizante desde la provincia de Entre Ríos a la del Chaco). Mientras esperan el arreglo, Leni se topa en un ahí nomás con alambrados y plantaciones de algodón, y aunque forman parte para ella de un "paisaje desolador" (76) le brindan una tregua frente a los sermones y el control paternos; por su parte, Tapioca recurre, bajo la guía de Brauer, al campo abierto cercano al taller, donde encuentra una interpretación tranquilizadora de sus miedos infantiles: la temida luz mala de la leyenda rural es simplemente el reflejo de huesos de animales muertos.

De esta novela, entonces, me interesa destacar una tercera escena literaria: la tormenta vespertina que sacude algunas horas del día y poco más en que transcurre la acción. Un vendaval impide al pastor y a su hija seguir viaje y —en una versión desviada del cuento de Borges "El Evangelio según Marcos" - los obliga a convivir con ambos lugareños, y provoca cambios. La palabra del pastor protestante hace mella en Tapioca, que deja el páramo norteño en busca del destino que Pearson le anuncia: ser un nuevo Cristo. Del vendaval se dice en la novela que fue "un momento único y completo donde todos fueron uno solo" (125). Desde el costado de la ruta, Brauer imagina así los saldos de la tormenta:

Voladuras de ranchos, destrozos en los sembrados, animales muertos, víctimas humanas [...] Por fin aire limpio, sin esa tierra seca flotando todo el tiempo [...] este polvo de muertos [...] A la luz suave de un relámpago, [Brauer] vio el asfalto brilloso, las copas de los árboles lavadas, como recién nacidas, hasta los esqueletos de los autos parecían piezas nuevas, listas para echarse a rodar otra vez en la ruta. (146)

Se vuelan ranchos, sembrados, animales, condensados todos en la imagen del polvo (un polvo de muertos). Lo que sucede a esto es aire limpio, frescor y brillo que se cifran en lo nuevo, lo que está listo, como Tapioca evangelizado, para salir a rodar. Polvo versus limpieza sería la fórmula del después de la tormenta. Ahora bien, ¿qué pasa con esa barrida? La sintaxis del título de la novela lo anticipa al poner al viento como sujeto: si lo que el viento se llevó es la ya impracticable tradición rural, lo que quedaría es aquello que arrasa con esa tradición;

provincia (2007), o como zona de trabajo golondrina en la cosecha, el tendido de alambrado, o como posibilidad de reinstalación familiar como caseros de estancia de "gringos" en Ladrilleros (2013). 
es decir, nuevas escrituras en las que el campo vuelve como objeto de otras imaginaciones que revisitan esa zona, ya despejada de la carga semántico-ideológica e interpretativa que en otros momentos de la cultura argentina adquirió lo rural, pese a que, como dice la novela, la salida del sol pueda borrar todo recuerdo de la lluvia (146). Porque lo que se borraría sería el recuerdo, y no así el paso del agua.

\section{Retornos y supervivencias del imaginario rural}

La puesta en relación de estas escenas literarias de escritoras diferentes, con novelas publicadas en tres momentos político-culturales productores de nuevos relatos renovadores o críticos (a grandes rasgos: los años sesenta, la poscrisis, el después del bicentenario nacional y el problema del campo) y las alegorías de expansión de dicha tradición quieren enmarcar el creciente interés en temas, ambientaciones, motivos rurales ${ }^{2}$ que se advierte en ciertas zonas de la cultura argentina contemporánea. Muchas expresiones artísticas pero también otros formatos más difíciles de especificar (que creí necesario incluir en este panorama) son partícipes de un clima cultural amplio en el que el problema de lo rural recobra visibilidad. No hace mucho La Nación mostraba una nota de tapa del escritor argentino Hernán Vanoli sobre una tendencia actual llamada neorruralismo: jóvenes profesionales urbanos de clase media optan por la reinstalación en el campo con la familia, no ya en busca de mejores ofertas de trabajo, sino de un nuevo estilo de vida (un nuevo vínculo con la naturaleza, la puesta en marcha de economías autosuficientes y ecológicas, la incursión en el cultivo de huertas orgánicas, el alejamiento de la contaminación auditiva y visual de los centros urbanos, el ingreso en otras sociabilidades, pero sin renunciar, por caso, al acceso a internet y a los saberes o experiencias que se traen de la ciudad). ${ }^{3}$ Por supuesto que no se trataría de una tendencia masiva y, además, convive con el éxodo de ciertas zonas rurales deprimidas y tóxicas, ${ }^{4}$ pero no otra cosa nos cuentan las recientes películas El campo (2012), de Hernán Belón,

2 Tomo el concepto de rural de manera amplia. La Diccionario de la Real Academia Española sostiene que rural proviene del latín (ruralis de "rus, ruris": campo) y que significa todo aquello perteneciente o relativo a la vida de campo y sus labores.

3 En la tapa se anuncia esta nota con el titular "Al campo, sin desconectarse de la city". Se puede leer en línea (http://www.lanacion.com.ar/1719058-la-era-del-nuevo-ruralismo). En la misma emisión se lee otra columna sobre el tema, de Julieta Quirós: "Ir de lo urbano a lo rural, la inversión del clásico itinerario".

4 En las páginas del Grupo de Reflexión Rural y Red Universitaria de Ambiente y Salud, por ejemplo, se registran varios artículos referidos al tema del éxodo a la ciudad desde el campo sojizado (que, por supuesto, no es el campo al que vuelven los "neorrurales"), por falta de infraestructura, déficit de servicios, por los efectos nocivos de los agrotóxicos, por escasez de trabajo. Pueden consultarse: https://www.facebook.com/gruporeflexionrural/?fref=ts 
y Aire libre (2014), de Anahí Berneri, en las que se ficcionaliza el fracaso rotundo de estos proyectos actuales. En ambas, las nuevas reglas del campo desestabilizan el orden estatuido, y no hay lugar ni para la reconexión familiar (las parejas se distancian o se son infieles; se deja olvidado a un hijo de noche en la casa de campo en construcción), ni para establecer nuevos vínculos (los habitantes del campo propio puede ser también los enemigos), ni para disfrutar del neobucolismo (el frío cala los huesos, la falta de confort acecha, el silencio pide gritos).

La propuesta de este trabajo es indagar algunas de estas insistencias de lo rural, asumiendo como punto de partida textos narrativos ${ }^{5}$ de la producción literaria argentina del presente. Una producción proliferante, heterogénea, en la que conviven autores consagrados (pienso en Blanco nocturno, 2010, de Ricardo Piglia; El desperdicio, 2007, de Matilde Sánchez; algunos libros de María Martoccia o Perla Suez) con nuevos escritores, ${ }^{6}$ que presentan textos muy celebrados (como Iosi Havilio con Opendoor, 2006; Hernán Ronsino con Lumbre, 2013; o la propia Selva Almada), y otros que cuentan con una obra todavía corta, o con algún libro solitario, o aún, temáticamente, sin descendencia (El molino, 2007, de Mariana Docampo; La hija de la cabra, 2012, de Mercedes Araujo; Corrientes, 2010, de Cristina Iglesia; unos pocos cuentos de Los posnucleares, 2011, de Lola Arias; Una idea genial, 2008, de Inés Acevedo; Brandsen, 2013, de Marcel Pla; ¿Sueñan los gauchoides con ñandúes eléctricos?, 2013, de Michel Niva, entre otros). ${ }^{7}$

5 El interés por el campo es evidente también en mucha poesía argentina actual, escrita por poetas más conocidos, como Diana Bellesi u Osvaldo Aguirre, y otros todavía con menor difusión y circulación (Diego Colomba, Alfredo Brescia, Cristian Molina). Por lo demás, en 2013 hice la curaduría de una emisión de la revista argentino-brasileña Sala Grumo que denominé "Nuevas ruralidades", y allí incluí una antología de poesía sobre el campo titulada "Reunión en lo abierto" en la que participaron algunos poetas con bastante producción como Carlos Batillana, Silvia Jurovietzky, y otras nuevas firmas, en su mayoría femeninas, muchas de las cuales también tienen una producción narrativa con el campo como protagonista o emplazamiento: Mariana Docampo, Vanesa Guerra, Mercedes Araujo, Cristina Iglesia, entre otros. Este dossier también contiene una crónica de Selva Almada, "Verano silvestre", que cuenta sus veranos en el campo familiar, un ensayo de Fernanda Alarcón sobre la tercera parte de Historias extraordinarias (2008) de Mariano Llinás, justamente ambientada en una finca, y una reseña de mi autoría sobre la obra de teatro Todo lo demás no importa, de Andrea Chacón Álvarez, que traspone dramáticamente algunos relatos de Sara Gallardo, una autora célebre, como se dijo, por sus primeras novelas de ambientación rural. Puede leerse en: http://www.salagrumo.org/notas.php?notaId=190

6 Digo "nuevos escritores" en el sentido de Beatriz Sarlo, es decir, escritores que forman parte de la literatura que se está escribiendo al mismo tiempo en que se producen las primeras intervenciones críticas sobre ella. No tomo la edad de nacimiento como factor para intentar caracterizar algunos de los gestos de estos escritores, cuyos años además arman un amplio arco etario.

7 Vislumbro algunas razones por lo pronto conjeturales de esta situación: la juventud y, por qué no también, los tiempos de sus hacedores, las condiciones en que surgen y se editan esos 
Una suerte de vuelta al campo, entonces, que coincide, en los planos político, social y económico con un momento en el que el campo se afirma como un foco de interés, de disputa entre sectores, y en materia productora de nuevos relatos; y en el plano cultural, con un conjunto de especulaciones teórico-críticas que se interrogan sobre el estado del arte del presente. No trato de responder la pregunta de por qué el campo gana hoy potencia en la producción estética. Más bien, me interesa ver cómo esta revisibilización del campo es tramitada por algunas zonas de la imaginación artística y cultural contemporánea. La figura que quiero resaltar es la del retorno del imaginario rural como estímulo para la producción estética (y cultural) del presente, no para comprobar una cronología lineal de altas y bajas que explicaría evolutivamente el interés actual en lo rural luego de un abandono del tema, sino más bien la copresencia de materiales muy heterogéneos, y diferentes temporalidades en esa producción. ${ }^{8}$

primeros textos (concursos, premios), la nueva visibilidad, el picoteo o el abandono de temas. Por tomar solo algunos pocos de los casos citados: Mariana Docampo no vuelve a utilizar el campo como escenario protagónico (en $\mathrm{La} \mathrm{Fe}$ solo hay un relato mezclado entre varios otros sobre la pampa) y su producción pega un giro que llega a un extremo con su último texto, Tratado del movimiento (Buenos Aires: Bajo la luna, 2014), objeto híbrido que merodea entre la ficción científica, la metafísica, el ensayo, y se vale tanto de teorías apócrifas sobre el movimiento como de enlaces o videos de internet. Serán la provincia de Entre Ríos y la llanura pampeana el paisaje de la quinta dimensión (en las orillas de El Paranacito abundan nuevos asentamientos colectivos) y donde se observarán los desplazamientos alternativos, diferentes, heterodoxos, de vacas y caballos: "las vacas trazaron una línea diagonal desde la primera tranquera, adentrándose en el medio del campo, sin rumbo aparente, pero en hilera perfecta [...] En cuanto a los caballos, hubo dos momentos en que se desplazaron en grupo hacia la ruta de tierra y la cruzaron. Entonces, las vacas retrocedieron contra el alambrado y se golpeaban entre sí [...] La lengua castellana no alcanza para expresar lo que entonces vi. La única traducción posible es: 'los pájaros volaban hacia atrás. Las vacas se curvaban y daban vueltas alrededor de la tierra'. La palabra alemana que signifique 'movimiento sin orden' podrá expresar con más precisión lo que vi. Los parámetros estaban corridos. Tanto es así, que incluso mi cuerpo de mamíferos no soportó la permanencia en ese espacio 'otro', y me desintegré" (36 y 37 ).

Por su parte, Inés Acevedo, después de su primera novela que obtuvo la primera mención del Concurso Indio Rico 2008 de Autobiografía - editada por Mansalva, en 2010, y reeditada por la editorial barcelonesa Alpha Decay, en 2012-, no vuelve a ningún escenario campero y escribe Trilogía canina, que son tres relatos urbanos sobre perros publicados como $e$-book por la editorial digital Los-Proyectos. Por último, Brandsen (2013), que cuenta la historia de un hombre acosado por los restos del spleen que recorre sin rumbo una pampa intimidatoria (plagada de extraños, monstruos, deformes, toxicidad), es la primera novela de una trilogía de Marcel Pla (hoy autor y hace poco el Señor Plaza, uno de los personajes del celebrado Banco a la sombra de María Moreno).

8 Un regreso que - creo- encontraría una ilustración en las escenas literarias del principio de este trabajo, ya sea al liberarse la llanura, propiciando la supervivencia de la historia del joven heredero rural en otros relatos (vimos que su muerte era tan solo una opción más) o desvirilizando el campo y poblándolo de outsiders; ya sea infiltrando el pasado, lo supuestamente 
Hoy podemos ver coexistir una novela como Blanco nocturno, donde leemos una rescritura de la tradición literaria vinculada al campo en clave genérica (un policial donde se investigan crímenes, se cita el Martín Fierro y se hacen evidentes referencias al Facundo); El desperdicio - la novela de la pastoral de la desnacionalización liberal y la globalización como ha propuesto Fermín Rodríguez (2011) - en la que la vuelta al campo, ya librada de un pasado patriótico y promisorio que, sin embargo, late en el horizonte interpretativo, encuentra una pampa desmantelada, con economías precarias y ocupada por conteiners y homeless rurales; y, también, por tomar un caso bien dispar, el reality show Cuestión de campo (2014). ${ }^{9}$ “Campo o ciudad?” era la pregunta que la conductora Claribel Medina hacía a los participantes que bajarían de peso en la experiencia rural o en la urbana. Fue una emisión especial del conocido Cuestión de peso asesorado por los doctores Cormillot, que actualizaba en clave bizarra (e involuntariamente paródica) la tradicional oposición ciudad-campo y sus metáforas (la tentación gastronómica, el confort, el transporte versus la alimentación saludable, autogestionada y la marcha a pie). La locación era la estancia San Antonio (la pampa bonaerense turística con animales en corral, mucho verde, tractores y sitios para tareas rurales). Allí los conductores (también médicos y entrenadores) esperaban disfrazados de paisanos a los pacientes-participantes. La consigna era adelgazar retirándose al campo, un objetivo real atravesado por ficciones guionadas (es un show de realidad) de celos, peleas, flirteo, emociones y hasta performances eróticas: la chica recuperada de peso se paseaba en bikini en la carreta como caso ejemplar del triunfo del tratamiento, que la había vuelto no solo saludable, sino sexualmente apetecible según parámetros deducidos de una economía machista de asignación del deseo. La consecuencia-castigo de no pasar la balanza en el campo era la vuelta a la ciudad pútrida y amenazadora. ${ }^{10}$

obsoleto (el polvo) en un presente expansivo: un viento que arrasa, que desperdiga en múltiple dirección, que se desplaza hacia distintos formatos, pero deja el recuerdo de la lluvia, las huellas de la tormenta.

9 Por supuesto, este producto mediático obedece a otras lógicas (a la del mercado televisivo, y hasta a una suerte de biopolítica de los cuerpos: el mandato de estar sano y flaco), pero también, como se sabe, se construye con modalidades de la ficción (el programa está casi todo guionado, hay reparto de roles y emociones, ambientaciones, disfraces) y, en este caso puntual, se construye sobre imaginarios rurales deudores de la tradición literaria.

10 No sé cuál podría haber sido la consecuencia de un error en la polémica propuesta del reality o doc show norteamericano Born in the Wild, 2014 (Canal Lifetime, propiedad de A+E Networks y Sony Entertainment), inspirado en un video que se viralizó en la web en el que se muestra a una mujer desnuda, aunque adornada con bijouterie, pariendo en medio de la naturaleza y que estaba al mismo tiempo estaba siendo filmada. Este video puede verse en http://www.videopartos.com/parto-en-la-naturaleza/. El reality, entonces, convocaba a mujeres embarazadas 
Ahora bien, también en el teatro encontramos marcas de este interés por lo rural, desde la propuesta experimental ${ }^{11}$ de Federico León con Cachetazo de campo (1997), pasando por obras como Llanto de perro (2005) de Andrés Binetti, Fauna (2013) de Romina Paula, Campo cascada (2014) de Gabriela Bejerman (sobre textos de Jane Bowles) hasta la recientísima Terrenal (2015) de Mauricio Kartún, por poner algunos casos. Un arco en el cual el choque cultural entre ambientaciones y personajes urbanos y rurales provoca tanto una ilusión de sosiego ("El campo" mediando entre las confesiones, reproches y llantos de una madre y una hija despojadas de "lo urbano" en plena pampa) como el absoluto malentendido (el Instituto Nacional de Estadísticas y Censos que llega a un rancho en mitad del campo, y un moderno living urbano cruzándose con un paisaje rústico), y coexiste con la recreación de mitos ancestrales o inventados, que así como son procesados por tópicos y retóricas rurales, abogan también por una teoría de la representación y del hecho teatral. ${ }^{12}$

no primerizas, disconformes con sus previas experiencias urbanas y sobremedicalizadas, para que fueran a dar a luz al campo - entendido como terreno alejado, fuera de poblado, como el dador de condiciones "naturales" para remedar el parto de tiempos ancestrales, al aire libre y sin asistencia profesional (un aislamiento al que sin embargo sí llegaría el registro de la cámara). Por supuesto, en estos casos no se trata del campo o el ámbito rural, sino de una naturaleza idealmente despojada de rasgos culturales, pero lo interesante es que la idea de la huida de la ciudad para llevar adelante estas prácticas ancestrales tan naturales como salvajes (el parto) actualiza un derivado de la dupla campo/ciudad como naturaleza/cultura.

11 En el prólogo a Teatro de la desintegración (1999), donde se publica la obra de León, Martín Rodríguez propone que Cachetazo de campo pertenece a lo que Osvaldo Pellettieri denominó teatro de la desintegración, "una poética emergente en los años noventa basada en una dramaturgia que entrega al lector-espectador imágenes en bruto, ambiguas, fruto de una realidad fragmentada".

12 A estas menciones cinematográficas y teatrales se pueden agregar muchos ejemplos más, algunas las trabajo en el apartado "Campo adentro". En el cine, toda la producción de Lucrecia Martel, Los rubios (2003) y La rabia (2008), de Albertina Carri; algunos tramos de la película Historias extraordinarias (2008) de Mariano Llinás que se localizan en el campo-estancia con la historia de las dos hermanas y su padre, y los oficios hogareños y rurales. Otros ejemplos muy recientes de cineastas varones que hacen regresar a sus personajes al campo bonaerense de Coronel Villegas y a una colonia de alemanes del Volga situada en Entre Ríos, respectivamente, son las películas, estrenadas en el marco del Festival de Cine Independiente, BAFICI 2012, Villegas, de Gonzalo Tobal, y Germania, de Maximiliano Schonfeld. Otros ejemplos actuales los encontramos en La tercera orilla (2014), de Celina Murga, y en el documental De mujeres argentinas como la Lola (2015), de Silvina Segundo, que cuenta la vida de Lola, una campesina argentina que además escribe un diario íntimo sobre su vida en el campo como trabajadora y retrata a otras mujeres campesinas. También en el teatro vemos este interés con Rancho (una historia aparte), 2004, de Julio Chávez, y muchas otras obras de Mauricio Kartun recopiladas en Tríptico de la patronal (Atuel, 2012). 
Por otro lado, en 2013 se pudo visitar en Buenos Aires dos muestras plástico-visuales, curadas ambas por Rodrigo Alonso: "Genealogías del campo argentino" sobre obras de Luis F. Benedit (en la Colección de Arte Fortabat) y "Hacia una poética de la producción" de Ana Lía Werthein (en el Centro Cultural Recoleta). ${ }^{13}$ Estos títulos se abren hacia imaginarios y temporalidades diferentes para referir al mundo rural: "genealogías" (al pasado) y "producción" (al presente), que son, además, sus sustentos conceptuales. En la retrospectiva de Benedit conviven obras heterogéneas (cuadros, instalaciones, maquetas y esculturas) que indagan los múltiples orígenes y aportes que podrían achacársele al campo argentino (la Conquista y los caballos, la campaña del desierto y la tierra anexada, la inmigración, la tecnología, etc.) y bucean en las costumbres gauchas (la doma, la yerra), las leyendas rurales (el basilisco), y en la tradición de la iconografía rural y el vocabulario y refranero criollo (Florencio Molina Campos, Tito Saubidet, entre otros). Por su parte, Werthein, cuyo abordaje de lo rural está vinculado con sus experiencias de niña en el campo familiar, pero sobre todo con su condición actual de productora, asume una mirada artística acerca del proceso actual de la producción agropecuaria, haciendo hincapié en las innovaciones tecnológicas para el cultivo y almacenamiento - que han sido de invento o rediseño nacionales - como la siembra directa (el suelo no es alterado con arado) y la silo bolsa (símbolo del avance rural dado por el acopio directo de granos en los propios campos, sin traslados, para su futura comercialización). Por tomar un ejemplo, Werthein se apropia estéticamente de la silo bolsa con una enorme instalación, cuyo soporte son las bolsas plásticas que se usan en el campo, y sobre ella superpone, al menos, dos temporalidades e imaginarios rurales: a la reproducción de los códigos de lectura que hacen los satélites computarizados aéreos le sobreimprime el dibujo de un gaucho a caballo, que sigue las líneas de ese lenguaje técnico como si fuera la huella.

Desde 2006 existe el ciclo de lectura multimedia Carne argentina, coordinado por Julián López, Alejandra Zina y Selva Almada, que ocurre en Buenos Aires, cuya frecuencia es hoy estacional. La experiencia Carne argentina cuenta con intervenciones de escritores, cineastas y artistas plásticos cuyos textos "bastardos" (así se los llama por la no pertenencia a un género determinado y la apertura de registros) van acompañados de proyecciones de video, música,juegos de iluminación (y hasta eventuales platos criollos). Digo experiencia, porque la idea es darles nuevas existencias al texto que se presenta, colocarlo en una especie de afuera de la

13 En octubre de 2014, Werthein expuso en la sala del Jardín Botánico de Buenos Aires una muestra titulada Del campo a la ciudad. 
escritura y de la lectura (sobre todo la silenciosa y en soledad), espectacularizarlo, y propiciar un nuevo modo de difusión de lo literario más allá de sus marcos y en un contexto de asociaciones y de sociabilidad (Laddaga, "Espectáculos"). El título del ciclo - Carne argentina - también haría tándem - ¿por qué no? - con el del blog Gran pato criollo de Inés Acevedo - la autora del referido Una idea genial - que registra la cotidianeidad pero en la ciudad de la bloggista, cuyos posteos versan sobre temas variados como el crecimiento del hijo o el impacto causado por la lectura de fuan Moreira. ${ }^{14}$ El concepto de las colecciones Carne argentina - cuya promoción se da mediante las redes sociales y los cada vez menos utilizados e-mailing y blog - se monta sobre una retórica y una performance del mundo rural: el lugar de encuentro es el "frigorífico"; los espectadores son el "público vacuno"; el archivo es "nuestra memoria carnívora"; una fórmula de despedida es la del "abrazo jugoso"; y alguna vez los participantes respondían cuál era su corte de carne favorito. ${ }^{15}$

14 El enlace al blog es http://granpatocriollo.blogspot.com.ar/2008/12/nueva-entrada.html. Transcribo literalmente una entrada de 2003: "es la historia de la semana. ¿Por qué no existirán inyecciones Martín Fierro? que te las pongas y entres en consonancia con su problemática... anoche mientras se me bajaba la presión, leía un libro que cada vez me sorprende más, Juan Moreira de Gutiérrez... no se puede creer qué escenas cinematográficas... imágenes más repetidas: las lágrimas de Juan Moreira se esconden entre su barba como rocío los paisanos se largan a llorar Juan Moreira acaricia tiernamente a su caballo y besa a su perro cacique en el hocico Juan Moreira y Julián se abraza a Juan Moreira y Julián se miran a los ojos comprendiendo instantáneamente sus sentimientos Juan Moreira es una inyección que me va a durar, y Martín Fierro fue una inyección en su momento, créase o no, el texto es fascinante, lleno de palabras otra vez, por qué no nos dejarán analizar solo las palabras? en Juan Moreira aparece por ejemplo la palabra 'gaucha'. nunca antes habíamos vista esa palabra escrita, ni siquiera soñamos con esa palabra. alguien la escuchó decir alguna vez? pero está en Juan Moreira. muy loco. aparte Gutiérrez y Arlt son un solo corazón".

15 El blog es http://ciclocarneargentina.blogspot.com.ar/. Así es la promoción en Facebook de la Colección Invierno 2014 del ciclo Carne Argentina, que se llevó a cabo el viernes 15 de agosto a las 21 horas en La Cazona de Flores, con las lecturas de Ramón Ayala, Mercedes Araujo, José Villa, Mariana Enríquez, Pedro Mairal: "Mientras preparamos el escenario para nuestra majestuosa Colección Invierno, les contamos a los que no nos conocen que el CICLO CARNE ARGENTINA ya va por su $9^{\circ}$ temporada. Lo concebimos como un espacio donde puedan convivir diferentes estilos, autores, generaciones y gustos lectores. La narrativa se mezcla con la poesía, la crónica periodística con la traducción, el cuaderno de notas con el ensayo. Del mismo modo, comparten sus lecturas escritores consagrados con escritores emergentes. Desde febrero de 2014, hacemos el ciclo en La Cazona de Flores. La entrada es libre y gratuita. La dirección y selección de los invitados está a cargo de Selva Almada, Julián López y Alejandra Zina. El video de apertura es de Rusi Millán Pastori [ElrusiMonobestia]. La selección musical de Sebastián Pandolfelli. El registro fotográfico y fílmico está a cargo de Guillermo Valdez. Y el diseño de los flyers es de Nicolás Ferraro". Hay otros emprendimientos culturales de este tipo en los que se promueve la vuelta de la escritura a la experiencia, por ejemplo el Grupo 
¿Qué pensarían de esta oda a la carne los adeptos a la practicada dieta paleolítica, para quienes la carne es la base de la nutrición del hombre desde el principio de su existencia, aún más natural y saludable que cualquier oferta vegetariana? Con esto no quiero decir que la dieta paleo sea una expresión directa del interés por el mundo rural, pero en su planteo actualiza otra de las dicotomías vinculadas con ese orbe: naturaleza/cultura. Y para su divulgación esta filosofía de vida que añoraría un remoto estadio protorrural no solo recurre a materiales provenientes del campo más coyuntural (Lucas Llach, uno de sus cultores, asegura que los hombres, como las vacas, nos hemos metido en nuestros propios feedlots, y da las pautas para salirse de allí), sino también a las redes sociales y nuevos formatos como el blog y a lo que podría llamarse un espectáculo gastronómico: algunas noches el mesón Como sapiens, ubicado en Recoleta, ofrece un menú paleo a los comensales que reserven y estén dispuestos a compartir mesa y cenar en comunidad. ${ }^{16}$

¿Qué pensarían, sigo, de aquella oda del ciclo de lectura, de aquella dieta, incluso de la poética de la producción de Werthein, quienes nos ponen en constante alerta - como, por referir un ejemplo reciente y resonante, la periodista Soledad Barruti con su controversial libro Malcomidos, de 2013- sobre las consecuencias insanas de los modos actuales de producción en el campo, que es de donde vienen hoy los alimentos (uso de fertilizantes químicos, plaguicidas; efectos de la sojización en el suelo de siembra; feedlots y criaderos artificiales que

Alejandría, que se autodefine como "un modo de escritura, una gran novela sin terminar que venimos escribiendo hace diez años", y Centro Enjambre (pequeño centro de investigación sobre escritura). Para leer sus editoriales ver: http://elgrupoalejandria.blogspot.com.ar/2014/03/ nuestra-editorial.htmly; http://www.centroenjambre.com.ar/formas_de_trazar.php.

16 La paleoalimentación o paleodieta o dieta del hombre de las cavernas (nómades que viven de la caza, la pesca, la recolección) tiene cada vez más adeptos mundialmente, que no solo quieren cuidar su figura, sino alimentarse saludablemente, alimentarse con lo que corresponde a nuestra especie. En Buenos Aires, es el economista Lucas Llach uno de sus principales cultores, al punto de que ha abierto un mesón paleo que se llama Como sapiens en un departamento de un edificio de Recoleta y a puertas cerradas. Allí, en mesas comunitarias, con previo turno, y solo los viernes por la noche, la gente puede disfrutar de un menú que intenta reconstruir la dieta típica previa a la invención de la agricultura y sus productos y derivados como la harina, el azúcar, los lácteos, el arroz. Un menú hecho sobre la base de carnes, verduras, frutas, tubérculos y mariscos. Un ejemplo: "Entrada: pincho de boquerones; Primer plato: escabeche de codorniz; Plato principal: carré de cerdo al pomelo con puré de batatas y peras con papas pay; Postre: gelatina de torrontés". El menú incluye media botella de vino (Bodega Humanao) y café. Se puede visitar http://alimentacionsapiens.blogspot.com.ar/2014/08/alimentacion-sapiens-unexperimento.html 
remplazan el ancestral pastoreo; la alimentación a base de granos y antibióticos de animales herbívoros)? ${ }^{17}$

La obra teatral En la huerta (2012), de Mariana Chaud, ${ }^{18}$ se basa en la huida de la ciudad a la chacra familiar de un joven atormentado que intentará administrar con nuevas metodologías (un circuito parecido al de los neorrurales de la nota de Vanoli). En el campo se encuentra con un peón que maneja la finca con otros saberes rurales y con quien, no sin conflictos (de idoneidad, de competencia física, de proyectos rurales y de deseo sexual), realizará una huerta orgánica sin mediación industrial, guiado por El horticultor autosuficiente, de John Seymour. Una huerta orgánica, entonces, que así como simboliza cierta pureza, excusa para nuevos descubrimientos sexo-afectivos y recala en pares opositivos del tipo naturaleza/cultura, natural/industrial, tradición/modernidad, constituye hoy una práctica rural establecida y representada (recordemos la huerta orgánica de la madre de Inés en Una idea genial) ${ }^{19}$ una práctica urbana que incrusta el

17 El documental austriaco We feed the world (2005), de Erwin Wagenhofer, muestra, desde una perspectiva crítica, las consecuencias de la masificación de la producción de alimentos, y advierte la irresponsabilidad del consumo promovido también por la creciente industrialización en el mundo globalizado.

18 Hace un tiempo otra versión de esta obra, llamada El horticultor autosuficiente, formó parte del Ciclo Manual que se dio en el Centro Cultural Ricardo Rojas. En esa primera versión quienes se encontraban en una chacra eran un hombre y una mujer de diferentes extractos socioculturales (un jardinero y una socióloga); mientras ella se afana en cambiar su vida urbana y se dedica a hacer una huerta orgánica guiada por el manual El horticultor autosuficiente (1978), de John Seymour, ambos comienzan a sentirse atraídos sexualmente. Luego la autora mantuvo la historia pero adaptándola a la relación entre dos hombres.

19 Así la autobiógrafa narra el proyecto de su madre que, como pasó con el del tambo de su padre y con todos los emprendimientos que asumen, le sale mal y lo abandona: "Poco después de su vida mi mamá abrazó con fervor la causa de la huerta orgánica. Un sistema revolucionario que se valoriza porque produce alimentos libres de fertilizantes y porque su concepción es el aprovechamiento inteligente de la naturaleza. Allí, todo lo inservible se vuelve útil: yuyos se transforman en abono, excrementos en fertilizantes, malas hierbas como la ortiga son poderosos venenos contra hormigas, plantas coloridas son espantapájaros, lechuga repele a mosquitos, rúcula crece mejor a la sombra del zapallal. Y un sinfín de cosas. Entre mi papá y mi mamá hubo un enfrentamiento a causa del modo de remover la tierra. Hasta el momento se creía que era necesario darle vuelta por completo con la azada hasta que la parte negra y fresca quedara afuera, desprendiendo miles de mosquitos diminutos. Pero mi mamá y el cuadernillo del INTA insistieron en lo contrario: la tierra debía ser removida, nunca dada vuelta, los nutrientes que están en el interior deben permanecer allí sin salir a la superficie, donde se desperdiciarían" (40). Y más adelante dice: "Ninguno de los proyectos que tuvo mi mamá funcionaron: hacer una huerta orgánica, fabricar quesos, plantar frambuesas, poner colmenas, criar lombrices, plantas aromáticas, chanchos. Todo salía mal, porque faltaba mano de obra, dinero para invertir, o la parte comercial no estaba resuelta. Entre mi papá y mi mamá no hacían un Erdosain" (Acevedo 48). 
campo en balcones y terrazas (las huertas orgánicas en cajón), y hasta un programa biopolítico nacional de seguridad alimentaria, capacitación y supuesta inclusión social (Prohuerta del Instituto Nacional de Tecnología Agropecuaria de Argentina). ${ }^{20}$

Sin duda, dentro del imaginario rural una de sus grandes protagonistas sigue siendo la oposición campo-ciudad y los fundamentos imaginarios histórica y culturalmente variables impuestos sobre ella. En Aquí América Latina (2010), Josefina Ludmer especula que desde fines de la década de los noventa el mundo ya no sería bipolar. Afectadas también las artes, habrían dejado de funcionar dicotomías tradicionales como campo/ciudad. Según Ludmer, la imaginería urbano/ rural promovería, antes que oposiciones, la superposición y la desdiferenciación (los dos regímenes centrales de la imaginación pública del presente). ${ }^{21}$ Más que en el agotamiento total de la tradicional dicotomía, o incluso en la idea de una ciudad absorbiendo al campo, o de una fórmula niveladora del tipo ciudadcampo, creo que lo rural se presenta hoy todavía diferente de su par conceptual dicotómico tradicional (la ciudad y en especial Buenos Aires), pero también como un polo menos dependiente de ella, que comparte visibilidad con otros espacios y materiales ficcionalizables (por ejemplo, las mismas "islas urbanas" de Ludmer). ${ }^{22} \mathrm{El}$ campo es menos un sitio homogéneo que un espacio expandido y expansivo, una renovada cantera de imaginarios, materiales, representaciones, temporalidades y usos múltiples que conviven en la escena cultural contemporánea.

20 Es un programa del Instituto Nacional de Tecnología Agropecuaria y el Ministerio de Desarrollo Social de la Nación. En este enlace se profundizan el concepto y los objetivos del programa: http://inta.gob.ar/documentos/prohuerta: "El Pro-Huerta está dirigido a la población en condición de pobreza, que enfrenta problemas de acceso a una alimentación saludable, promoviendo una dieta más diversificada y equilibrada mediante la autoproducción en pequeña escala de alimentos frescos por parte de sus destinatarios".

21 Ludmer sostiene que las escrituras postautónomas saldrían de los marcos prefijados de la literatura e ingresarían en la imaginación pública, que define como un medio o una materia "real virtual, sin afueras [...] todo lo que se produce y circula y nos penetra y es social y privado y público y real [...] un tipo de materia [...] donde no hay 'índice de realidad' o de ficción y que construye presente" ("Aquí, América" 155-156).

22 Ludmer toma como ejemplos de islas urbanas la localización de muchas escrituras postautónomas, como las villas miserias de César Aira, el conventillo/yotibenco de Washington Cucurto, el zoológico de María Sonia Cristoff, la casa tomada de la serie televisiva Okupas. Pienso que hoy otros espacios con los que el campo compartiría visibilidad podrían ser algunos ejemplos de islas urbanas (el barrio, la villa), pero también el espacio transnacional, las islas Malvinas, el Cono Sur, entre otros. 


\section{Campo adentro}

Como señaló Sylvia Molloy, el campo fue tradicionalmente un espacio generizado como masculino, que funcionó como reservorio de los valores patrios. En virtud de El desperdicio, Molloy se detiene en el gesto fundante de Matilde Sánchez al versionar, a propósito del retorno al campo de Elena (una mujer, una letrada), una pampa librada de la mística virilizada. Mucho antes, la propia Sara Gallardo en su ópera prima Enero (1953), novela de ambientación rural, narra por primera vez en la literatura argentina la violación de la china de campo desde la perspectiva de la propia afectada. Ahora bien, poco después de la novela de Sánchez, hoy surgen nuevas firmas (en su mayoría femeninas) que se apropian de "esa escuela de hombría" (son palabras de Molloy) donde ya parecía haber pasado todo, reinstalan otros temas y redirigen la mirada y la narración del campo hacia personajes femeninos. Son en su mayoría escritoras que van y vuelven al lugar de origen para escribir; que abordan el tema y lo abandonan; que comparten la escritura con otras profesiones o actividades artísticas, y así trafican relatos y experiencias.

El campo de estas narraciones se perfila como un lugar tan inestable como propulsor de inestabilidades. Muchas de sus fábulas se sitúan en zonas liminares como vimos en Almada, y cuando aparece una ambientación más tradicional como la estancia, se recurre a formas heterodoxas de la autobiografía (en Acevedo y Docampo) que truecan cualquier épica rural o nacional por la experiencia personal y de escritura que desestabiliza, por un lado, el estatuto ficcional al fusionar personaje dramático con persona real y, por otro, las relaciones pasado y presente al contar la propia vida no ordenadamente, sino según percepciones subjetivas que mezclan temporalidades (por ejemplo, mediante la figura del aniversario).

El relato "Los que no duermen", de Lola Arias, procesado como guión técnico-cinematográfico, imagina ambientaciones postutópicas y apocalípticas también en la estancia dentro de un mundo posnuclear, habitado por personajes somnolientos, un poco masculinos y un poco femeninos, ${ }^{23}$ artistas, ciegos, que viven en un puro presente, con una perspectiva cortoplacista, sin ideas de futuro; subjetividades en fuga que van de la ciudad al campo y en nada se parecen a los peones, gauchos, paisanos o estancieros de la tradición rural. Quienes habitan este campo, anegado por las inundaciones (como en Cambaceres, Benito Lynch y Borges, pero también en Mariano Llinás y Almada), improductivo y sin trabajo (como en Sánchez), están deprimidos o se suicidan: la dueña no sale de la cama,

23 En "Animal de verano", de Arias, una primera persona cuenta que cada verano iba al campo con su padre. Allí descubría, por caso, cómo los peones a escondidas se referían a su patrón (su padre) con nombre de mujer. 
los gauchos se cuelgan de los árboles, las chinas meten la cabeza en el horno, los caballos se ahogan. Este cuento-guión de Arias abunda en íconos pamperos devaluados (vacas flacas, taperas, casas quemadas) y en figuras de circularidad y opresión. ¿Por qué no pensar esas imágenes de la devaluación rural en relación con la inestabilidad genérica del relato - que se inicia justo con la indicación del travelling - promoviendo nuevas existencias por fuera de la escritura y del libro como la de la espectacularidad de la pantalla grande o el teatro, donde Arias ha dado que hablar justamente con sus biodramas?

Parecieran ser otros los temas - acaso un síntoma de conexión de esta literatura con su época- que se negocian en estos espacios, sobre los que, sin embargo, sobreviven huellas de su pasado ideologizado. Así se instalan la diversidad sexual (la pasión homosexual entre los hijos de los ladrilleros en Almada; la narración a cargo de una mujer que mantiene relaciones sexoafectivas con hombres y mujeres, en la ciudad y el campo en Havilio; el deseo homoerótico del patrón de estancia por el intruso en el filme Deshora, 2014, de Sarazola-Day) y nuevos modos de narrar el acoso y abuso sexuales. En la película Los dueños, a la tradicional lucha de clases se le sobreimprime el acoso sexual, pero esta vez de patrona a peón, a quien incluso obliga a travestirse de mujer con su propia ropa. Por su parte, Almada se encarga de procesar aquellos temas en distintos géneros y formatos. Así el abuso de un familiar se presentifica en su autobiografía, en crónicas sobre el campo, ${ }^{24}$ en su libro de no ficción sobre tres femicidios provinciales. ${ }^{25}$ Quiero decir: este tráfico temático se da en géneros híbridos, inestables entre ficción y realidad, literatura y periodismo, objetividad y perspectiva subjetiva, documento y leyenda, y mediante un uso peculiar de los archivos (como el de los casos de feminicidios).

A esto se suma el paso de Almada por la creación colectiva y el guión de historieta para instalar en la pampa - en la colonia psiquiátrica Opendoor, en cuyos alrededores Havilio sitúa zonas de su novela - un tema del pasado reciente (la última dictadura a la luz del hijo enfermo de Videla que estuvo allí

24 Por ejemplo en "Verano silvestre" Almada cuenta: "había un primo viejo de mis tías que se había enamorado de una de ellas, de la más grande. Ella lo había rechazado por feo, por viejo y por pariente (decía que, de casarse, los hijos les iban a nacer mongólicos) y él había intentado forzarla. El episodio no se había repetido, pero sabíamos que la acechaba. Cuando andábamos por la calle desierta, oíamos crujir las plantas de maíz o de sorgo que crecían a los lados y pensábamos que era él, el Tatú, que en cualquier momento saldría del sembrado y nos cortaría el paso, listo para violarnos". La crónica completa puede leerse en la revista virtual Sala Grumo: http://www.salagrumo.org/notas.php?notaId=187

25 En el regreso de la democracia se cometen, entre otros, los feminicidios de María Luisa Quevedo, María Andrea Danne y Sarita Mundín. Hasta el día de hoy no han sido resueltos. 
internado) procesado por una ucronía (el género literario del no tiempo, de la pura especulación sobre realidades alternativas, del qué hubiera pasado si...). En "El vástago", primera emisión de la historieta cuya autoría Almada comparte con Gabriela Cabezón Cámara e Iñaki Echeverría y que se publica desde 2014 en la revista Fierro, se da inicio a la otra historia, la que se ubica en la línea ucrónica, la del tiempo inexistente, el de "¿qué hubiese sucedido si...?". El título "El vástago" refiere al hijo real de Videla, que él mismo interna durante los años setenta en el establecimiento psiquiátrico Opendoor a causa de su enfermedad mental diagnosticada como oligofrenia. En la primera entrega se narra y muestra a dos personajes femeninos que circulan por "el loquero": la mucama de Videla que va de visita a llevarle dulces y cigarrillos al paciente y una guerrillera disfrazada de enfermera que está a la espera de la llegada de Videla para matarlo. Se trata de una espera que funcionaría en dos planos: en el de las inestabilidades del propio proceso creativo de la entrega mensual (los lectores tenemos que esperar un mes para ver su desarrollo que incluso podría estar sujeto a modificaciones) y en la temporalidad que impone la sospecha: la historia podría cambiarse ficcional y ucrónicamente solo si Videla, en lugar de mandar a su empleada, fuera él mismo a visitar al hijo que también oculta y hace desaparecer.

Hay lugar también en el campo para la trata de personas. A un año del bicentenario nacional, María Inés Krimer publica La inauguración (2011), que sitúa la fábula durante el reciente conflicto con el campo, en el lockout patronal de 2008, que se tradujo en cortes de ruta, atascamiento en la circulación de productos, servicios y personas. Esta novela procesa mediante un policial negro - un género tradicionalmente "masculino" y relegado del canon, es decir, del gender system patriarcal y del genre system hegemónico - un tema de candente actualidad (la trata de personas y la violencia machista) localizado en la pampa sojera actual, representada como circular, empañada por el humo, de la que es imposible escapar. En ella se construyen protagonistas híbridos y vacilantes: el jefe del prostíbulo, quien es también un productor rural, vende toros y mujeres al mismo precio; la "víctima" en el campo, que es victimaria en la ciudad (de donde se fuga tras matar a un tío abusador), está aislada pero informada del afuera social por la televisión (programas rurales, noticieros y el show de Susana Giménez), la radio, la revista Caras, y el camión con parlantes que anuncia la inauguración rural. De esta joven sin nombre tampoco sabemos si sufre o goza de los momentos de mayor violencia, que aparecen seguidos de una extraña y perturbadora cosmética del encierro que remite al ambiente urbano: el uso de la planchita de pelo o el entrenamiento en el modelaje (una Valeria Mazza de las pampas). Un personaje en transición alojada en un lugar también de paso (la casa-feedlot es el entreacto 
entre la captura y el envío a prostíbulos del sur), y que, como los vacunos, está en espera de ser rematada al mejor postor o de padecer un síndrome de Estocolmo con su raptor o ser parte activa de la red de trata.

El campo sojizado y la presencia en este de otros temas y protagonistas mujeres reaparece en Distancia de rescate (2014), de Samanta Schweblin. Allí el espacio rural, contaminado por agrotóxicos que envenenan, deforman cuerpos, causan muertes y degradan los vínculos familiares (ante todo, la cercanía o distanciamiento entre madres e hijos), entra en relación con una teoría del modo de narrar. Una teoría del detalle y la relevancia narrativa que produce, entonces, un nuevo relato rural, agusanado, contado a dos voces, cruzado por distintas temporalidades, marcado por los ritmos de la intoxicación y la urgencia por encontrar el punto exacto o la distancia de rescate antes de que llegue la muerte.

A todo este entramado temático ideológico se suman otros casos cinematográficos. En La rabia (2008), de Albertina Carri, aparece el sadomasoquismo en su versión rural: cepos, máscaras, poses y hasta los acuerdos consuetudinarios $\mathrm{BDSM}^{26}$ son deudores del mundo animal rural. Julia Solomonoff, en El último verano de la boyita (2009), filma la imposibilidad de ejecutarse en el campo lo que hoy se denomina identidad de género, un derecho adquirido por las nuevas legislaciones. A diferencia de $X X Y$, de Lucía Puenzo, donde Alex (nombre unisex), apoyado por una familia burguesa, puede elegir; al menor hermafrodita del filme de Solomonoff su propia familia (rústicos peones de estancia, gauchos judíos) lo quiere, aun sabiendo su condición, incluso viéndolo menstruar, no solo varón sino viril a fuerza de golpes, oficios y costumbres rurales como la escena de carrera de jinetes y caballos que cifra esta imposición. Pese a que ni siquiera se le permita la opción de transicionar de género, el tema aparece en mitad del campo.

En el marco de las discusiones sobre la transición, la liminalidad y la pregunta por el estatuto del arte en la cultura contemporánea, podríamos interrogarnos si esta renovada tematización de lo rural es la que demanda hoy el uso de estos diversos géneros, formatos disponibles, o si - al revés - es la expansión o redefinición de ciertas categorías convencionales las que propician y animan a un nuevo tratamiento de lo rural en distintos objetos y dominios, que así como exceden lo estético, parecerían convivir en aparente armonía.

Un espacio polisémico, el campo, que se muestra más cercano a las agendas del presente que saldando cuentas pendientes -estéticas, ideológicas- con el pa-

26 Es una sigla para referir a esta preferencia sexual acordada de antemano, y significa bondage, discipline, dominance, submission, sadism, masochism. 
sado; que se constituye en un material emergente para la producción simbólica actual(desde textos de narradores/as que entran y salen de ese tema hasta un ciclo de lectura que exterioriza la literatura hacia nuevas existencias o un producto mediático que lo espectaculariza), y así, en un zona de cruce de muchas reflexiones sobre la cultura y el arte contemporáneos: las inestabilidades de su estatuto, la copresencia de realidades o elementos heterogéneos, las relaciones heterodoxas con el tiempo.

\section{Obras citadas}

Acevedo, Inés. Una idea genial. Buenos Aires: Mansalva, 2010. Impreso. AA. VV. "Dossier: estados del presente". Grumo 7 (2008). Impreso. Agamben, Giorgio. “¿Qué es ser contemporáneo?”. Web.

Almada, Selva. Chicas muertas. Buenos Aires: Random House, 2014. Impreso. Almada, Selva. El viento que arrasa. Buenos Aires: Mardulce, 2012. Impreso. Almada, Selva. Intemec. Buenos Aires: Los-Proyectos, 2012. E-pub. Almada, Selva. Ladrilleros. Buenos Aires: Mardulce, 2013. Impreso. Almada, Selva. Una chica de provincia. Buenos Aires: Gárgola, 2007. Impreso. Almada, Selva. "Verano silvestre". Sala Grumo (2008). Web.

Almada, Selva, Gabriela Cabezón Cámara e Iñaki Echeverría. "El vástago". Fierro: la historieta argentina. Buenos Aires: La Página, 2014 - 43-51. Impreso.

Araujo, Mercedes. La hija de la cabra. Buenos Aires: Bajo la Luna, 2012. Impreso.

Arias, Lola. Los posnucleares. Buenos Aires: Emecé, 2011. Impreso.

Barruti, Soledad. Malcomidos: cómo la industria alimentaria argentina nos está matando. Buenos Aires: Planeta, 2013. Impreso.

Bejerman, Gabriela. Campo cascada. (Fecha de estreno: 7 de junio de 2014 en El excéntrico de la $\left.18^{\circ}\right)$. Impreso.

Binetti, Andrés. "Llanto de perro (Una vulgaridad contemporánea)". Dramaturgia argentina contemporánea. Buenos Aires: La Voz del Espejo, 2007. 15-35. Impreso.

Coelho, Oliverio. "Un viento con destino de clásico". $L a$ Nación, 29 de abril de 2012, 18. Impreso.

Contreras, Sandra. "Algo más sobre la narrativa argentina del presente". Katakay. Revista Crítica de Literatura Latinoamericana 3.5 (2007): 6-9. Impreso.

Contreras, Sandra. "Cuestiones de valor, énfasis del debate". Boletín/15: Centro de Estudios de Teoría y Crítica Literaria (noviembre de 2010): 129-137. Impreso.

Contreras, Sandra. "En torno de las lecturas del presente". Los límites de la literatura. Ed. Alberto Giordano . Rosario: Centro de Estudios de Literatura Argentina, 2010. 135-152. Impreso. 
Chaud, Mariana. En la huerta. (Fecha de estreno: 6 de junio de 2014, en El portón de Sánchez). Impreso.

Docampo, Mariana. El molino. Buenos Aires: Bajo la Luna, 2007. Impreso.

Docampo, Mariana. Tratado del movimiento. Buenos Aires: Bajo la Luna, 2013. Impreso.

Fernández Bravo, Álvaro. "Heterocronías: una especulación sobre lo arcaico-contemporáneo". Actas del III Congreso Internacional Cuestiones Críticas, Rosario, abril de 2013. Web.

Gallardo, Sara. Los galgos, los galgos. Buenos Aires: Sudamericana, 1973. Impreso.

Gallardo, Sara. El país del humo. Buenos Aires: Sudamericana, 1977. Impreso.

Garramuño, Florencia. Mundos en común: ensayos sobre la inespecificidad en el arte. Buenos Aires: Fondo de Cultura Económica, 2015. Impreso.

Giordano, Alberto. El giro autobiográfico en la literatura argentina actual. Buenos Aires: Mansalva, 2008. Impreso.

Giordano, Alberto. Vida y obra: otra vuelta al giro autobiográfico. Rosario: Beatriz Viterbo, 2011. Impreso.

Gras, Carla. "Cambio agrario y nueva ruralidad: caleidoscopio de la expansión sojera en la región pampeana". Trabajo y Sociedad 15.18 (2012): 7-24. Impreso.

Gras, Carla y Karina Bidaseca, dirs. El mundo chacarero en tiempos de cambio: herencia, territorio e identidad en los pueblos sojeros. Buenos Aires: Ciccus, 2011. Impreso.

Guerra, Vanesa. Cómo sopla el serpentino cuando no canta el gallo. Buenos Aires: Bajo la Luna, 2012. Impreso.

Havilio, Iosi. Opendoor. Buenos Aires: Entropía, 2006. Impreso.

Havilio, Iosi. Paraísos, Buenos Aires: Mondadori, 2012. Impreso.

Iglesia, Cristina. Corrientes. Rosario: Beatriz Viterbo, 2010. Impreso.

Instituto Nacional de Tecnología Agropecuaria. "Prohuerta", 7 de diciembre de 2011. Web.

Kartun, Mauricio. Terrenal: pequeño misterio ácrata. Buenos Aires: Atuel, 2014. Impreso.

Kartun, Mauricio. Tríptico patronal: Salome de Chacra-El niño argentino-Ala de criados. Buenos Aires: Atuel, 2012. Impreso.

Krimer, María Inés. La inauguración. Buenos Aires: El Ateneo, 2011. Impreso.

Laddaga, Reinaldo. Espectáculos de realidad: ensayo sobre la narrativa latinoamericana de las últimas dos décadas. Rosario: Beatriz Viterbo, 2007. Impreso.

Laddaga, Reinaldo. Estética de la emergencia: la formación de otra cultura de las artes. Buenos Aires: Adriana Hidalgo, 2006. Impreso.

Laera, Alejandra. "Sara Gallardo, más allá del paraíso". Escrito en el viento: lecturas sobre Sara Gallardo. Comps. Paula Bertúa y Lucía De Leone. Buenos Aires: Editorial de la Facultad de Filosofía y Letras de la Universidad de Buenos Aires, 2013. 33-46. Impreso. 
León, Federico. "Cachetazo de campo". Teatro de la desintegración, 25-58. Buenos Aires: Eudeba, 1999. Impreso.

Ludmer, Josefina. Aquí, América Latina: una especulación. Buenos Aires: Eterna Cadencia, 2010. Impreso.

Ludmer, Josefina. "Temporalidades del presente". Boletín/10: Centro de Estudios de Teoría y Crítica (2002): 91-112. Impreso.

Molloy, Sylvia. "Intervenciones patrias: contratos afectivos". Ponencia presentada en el XXIX Congreso de la Asociación de Estudios Latinoamericanos (LASA), Toronto, Canadá, octubre de 2010, mimeo. Impreso.

Montaldo, Graciela. De pronto, el campo: Literatura argentina y tradición rural. Rosario: Beatriz Viterbo, 1993. Impreso.

Nieva, Michel. ¿ Sueñan los gauchoides con ñandúes eléctricos? Buenos Aires: Santiago Arcos, 2013. Impreso.

Obedman, Julieta y Mercedes Güiraldes. Campo, la mirada infinita. Buenos Aires: Van Editoras, 2014. Impreso.

Paula, Romina. Fauna. Tres obras. Buenos Aires: Entropía, 2013. Impreso.

Piglia, Ricardo. Blanco nocturno. Barcelona: Anagrama, 2010. Impreso.

Pla, Marcel. Brandsen. Buenos Aires: Blatt y Ríos, 2013. E-book.

Quirós, Julieta. "Ir de lo urbano a lo rural, la inversión del clásico itinerario". La Nación, 16 de agosto de 2014. Web.

Rodríguez, Fermín. "La enorme tierra de lo que no hay". Revista de Cultural $\tilde{\mathrm{N}}, 15$ de julio de 2011. Impreso.

Rodríguez, Fermín. Un desierto para la nación: la escritura del vacío. Buenos Aires: Eterna Cadencia, 2010. Impreso.

Rodríguez, Martín. Prólogo a Teatro de la desintegración. Buenos Aires: Eudeba, 1999. Impreso.

Ronsino, Hernán. Lumbre. Buenos Aires: Eterna Cadencia, 2013. Impreso. Sánchez, Matilde. El desperdicio. Buenos Aires: Alfaguara, 2007. Impreso.

Sarlo, Beatriz. Ficciones argentinas: 33 ensayos. Buenos Aires: Mardulce, 2012. Impreso.

Schweblin, Samanta. Distancia de rescate. Buenos Aires: Random House, 2014.

Vanoli, Hernán. "La era del nuevo ruralismo". La Nación, 16 de agosto de 2014. Web. 


\section{Películas}

Belón, Hernán. El campo, 2012.

Berneri, Anahí. Aire libre, 2014.

Carri, Albertina. La rabia, 2008.

Llinás, Mariano. "Las dos hermanas", en Historias extraordinarias, 2008.

Murga, Celina. La otra orilla, 2014.

Puenzo, Lucía. XXY, 2007.

Solomonoff, Julia. El último verano de la boyita, 2009.

Sarasola-Day, Bárbara. Deshora, 2014.

Toscano, Agustín y Ezequiel Radusky. Los dueños, 2014. 